\title{
Is Rooftop Solar PV at Socket Parity Without Subsidies?
}

Title: Is Rooftop Solar PV at Socket Parity Without Subsidies?

Author names and affiliations:

Shelly Hagerman ${ }^{\mathrm{a}}$, Paulina Jaramillo ${ }^{\mathrm{b}}$, Granger Morgan ${ }^{\mathrm{c}}$

${ }^{\text {a }}$ Corresponding author - Shelly Hagerman

Department of Engineering and Public Policy, Carnegie Mellon University, USA 5000 Forbes Avenue. Baker Hall 129.

Pittsburgh, PA 15213

shellyhagerman@gmail.com

${ }^{\mathrm{b}}$ Paulina Jaramillo

Department of Engineering and Public Policy, Carnegie Mellon University, USA 5000 Forbes Avenue. Baker Hall 129.

Pittsburgh, PA 15213

paulina@cmu.edu

${ }^{\mathrm{c}}$ Granger Morgan

Department of Engineering and Public Policy, Carnegie Mellon University, USA 5000 Forbes Avenue. Baker Hall 129.

Pittsburgh, PA 15213

gm5d@andrew.cmu.edu

Keywords: solar PV; socket parity; grid parity; net metering; residential solar 


\begin{abstract}
Installations of rooftop solar photovoltaic (PV) technology in the United States have increased dramatically in recent years, in large part because of state and federal subsidies. In the future, such subsidies may be reduced or eliminated. From the homeowner's perspective, solar PV is competitive when it can produce electricity at a cost equivalent to the retail electricity rate, a condition sometimes referred to as "socket parity." In assessing the economic viability of residential solar PV, most existing literature considers only a few locations and fails to consider the differences in PV system cost and electricity prices that exist across the U.S. We combined insolation data from more than 1,000 locations, installation costs by region, and county-level utility rates to provide a more complete economic assessment of rooftop solar PV across the U.S. We calculated the break-even electricity prices and evaluated the reductions in installed costs needed to reach socket parity. Among the scenarios considered, we estimate that only Hawaii has achieved socket parity without the use of subsidies. With subsidies, six states reach socket parity, yet widespread parity is still not achieved. We find that high installation costs and financing rates are two of the largest barriers to socket parity.
\end{abstract}




\section{Introduction}

As a result of falling installation prices and federal, state and local incentives, recent years have witnessed a remarkable proliferation of rooftop photovoltaic (PV) arrays. At the federal level, incentives include the $30 \%$ solar investment tax credit (ITC) and rules that require utilities to interconnect sources of distributed generation. Many local, regional, and state governments provide a variety of subsidies including rebates, low-interest loans, performance-based incentives, grants, and various tax incentives (Database of State Incentives for Renewables \& Efficiency, 2013). Twenty-nine states, as well as Washington DC and three territories have renewable Portfolio Standards (RPS) that require that a percentage of electricity sold in the state come from qualifying renewable resources ("Renewable Portfolio Standard Policies," 2015). An additional eight states and one territory have renewable portfolio goals ("Renewable Portfolio Standard Policies," 2015) with targets of renewable generation between 2-25\% of total generation. While wind power has been the fastest growing renewable resource, and is expected

to be the largest contributor to the RPS targets (U.S. Energy Information Administration, 2014), solar is also playing a role, particularly because some state RPS programs require that a portion of solar power come from residential solar systems. Finally, many states have implemented net metering rules, which require distribution utilities to purchase surplus power produced by customers at retail rates, rather than the much lower wholesale prices at which the utilities buy most of their power (Database of State Incentives for Renewables \& Efficiency, 2015).

Subsidies and incentives for PV have largely been motivated by an understanding of the need to decarbonize the energy system, and by a desire to reduce the other externalities that arise from burning fossil fuels (Committee on Health, Environmental, and Other External Costs and 
Benefits of Energy Production and Consumption and National Research Council, 2010), and by a more general belief that renewable energy resources contribute to "sustainability." The hope is that by subsidizing deployment, market size will increase and costs will be driven down through innovation and economies of scale. Indeed, recent years have witnessed a dramatic fall in solar PV module prices, largely as a result of Chinese module production and the decline of polysilicon prices (as seen in Figure S1) that directly affect module costs (Honeyman et al., 2014; Kann et al., 2013; Kimbis et al., 2012). Today, the average cost of a typical rooftop PV installation is around a third of what is was in 1998 (Barbose et al., 2014). A breakdown of these installation costs can be seen in Figure S2. While electricity generated by PV still constitutes a very small fraction of total U.S. electricity generation, installations have grown rapidly, with capacity additions totaling over $4.5 \mathrm{GW}$ in 2013 and nearly $4 \mathrm{GW}$ during the first three quarters in 2014 (Figure S3) (Honeyman et al., 2014; Kann et al., 2014).

The recent growth in PV installations has sparked a growing number of news reports and press releases that argue that solar PV has already achieved "grid parity" or will reach grid parity in the near term (BusinessGreen.com staff, 2009; Parkinson, 2014; Richard, 2014; Shahan, 2014). Many of these articles reference an October 2014 market research report by Deutsche Bank's Vishal Shah and Jerimiah Booream-Phelps in which they argue that “....more than 10 US states are currently at grid parity and nearly all 50 states would be at grid parity by 2016 timeframe" (Shah and Booream-Phelps, 2014). Such news coverage typically neglects to report that this claim is based on the existence of the ITC and other policy mechanisms aimed at supporting the deployment of such renewables. There is uncertainty, however, about the long-term availability of such support. The ITC, for example, is set to expire for residential customers at the end of 
2016. Similarly, many of the grants and tax credits available from states and counties have either fixed capacity and/or time frames such that they may not be available to customers in the next few years. For example, the Iowa personal tax credit for residential customers will expire at the end of 2016 with the conclusion of the federal ITC for residential customers ("Solar Energy Systems Tax Credit (Personal)," 2015) and the Maryland rebate program will expire when funds are exhausted ("Residential Clean Energy Grant Program," 2015). Some states and electricity providers offer feed-in-tariffs (FITs) for renewable generation sold back to the power company at rates between 10-30 $\varnothing / \mathrm{kWh}$ (EIA, 2013c). These FITs aim to encourage rapid deployment of renewable energy and may over-compensate the solar system owner. Some utilities are thus beginning to instead design and implement value-of-solar tariffs that compensate system owners at rates comparable to retail electricity prices.

Claims of grid parity have also relied on the continued existence of net metering. A majority of the states with net metering policies also include caps on net-metered capacity, creating uncertainty about the future availability of net metering (Hetter et al., 2014). California utilities are now limiting the availability of net metering to future customers pursuant to Assembly Bill No. 327 (Perea et al., 2013) and other states/utilities may adopt similar limits. For example, Kansas and Oklahoma are allowing utilities to create new rate classes for distributed generation customers (Durkay, 2014), a change that could negatively affect the economics of solar PV dependent on how the tariffs are structured. On the other hand, Vermont is an example of a state that has raised previous caps on net-metering capacity (H-0702 As Passed by Both House and Senate, 2014). These examples illustrate that net-metering programs for residential customers are 
in flux across the country, which creates more uncertainty about the future economic viability of rooftop solar PV.

While widely used (Breyer and Gerlach, 2013; Farrell, 2012; Reichelstein and Yorston, 2013), the phrase "grid parity" is ambiguous. In 2013, Bazilian et al. argued that the term "...has become outdated and is generally misleading." Most analysts have used the phrase to indicate a situation in which "the total cost to consumers of PV electricity, adding in as many of the realistic costs as possible" (Branker et al., 2011) is less than or equal to the cost of power purchased from the grid at retail rates. Unlike Shah and Booream-Phelps (2014), others such as Farrell (2012), have excluded subsidies from their definition of grid parity. Some have also defined "grid parity" based on a comparison of the average levelized cost of electricity (LCOE) of solar PV systems with the LCOE of other energy technologies (Bhandari and Stadler, 2009). Branker et al. (2011) demonstrate the need for proper and transparent valuations using the LCOE of solar on a locational basis as factors such as insolation, electricity rates, and installed costs vary geographically. Bazilian et al. (2013) suggest that an LCOE comparison is an inadequate metric of "grid parity" because it hides complex interactions between variables that affect the economics of solar PV systems. Similarly, Paul Joskow describes LCOE as a "flawed" metric for evaluating intermittent resources (Joskow, 2011).

Since we are evaluating the economics of solar PV from the homeowner's perspective, and not for utility planning, we focus on the break-even electricity price required for socket parity. This method allows us to avoid making assumptions of future electricity prices, although increasing electricity prices will further improve the economics of solar PV. This method implicitly 
assumes that generation does not exceed the customer's instantaneous load or that excess generation can be valued at the retail electricity price. However, we explore the effect of these assumptions in a sensitivity analysis. The break-even electricity price is useful because a residential customer cares about the cost of electricity coming from their rooftop array as compared with the cost of the electricity they buy from their local utility. Hence, rather than "grid parity" we use the phrase "socket parity," which we define as occurring when the lifetime cost from the rooftop array is less than or equal to the lifetime price of purchasing electricity from the local distribution utility (Bazilian et al., 2013).

To evaluate socket parity, we developed an engineering-economic model that accounts for region-specific installation costs, solar radiation, and electricity prices. Under these assumptions, we evaluated whether residential solar PV systems are at socket parity without subsidies, expanding on the scope of previous work by modeling the economic viability of PV systems in over 1,000 locations across the U.S. Further, we systematically explored the effects of different parameters that influence the economic viability of solar PV including installation costs, financing costs, and annual maintenance costs.

\section{Methods}

\subsection{Break-even Electricity Price}

Our model calculates the break-even electricity price for an investment in a rooftop solar PV installation using pessimistic, best, and optimistic scenarios for residential customers. The primary inputs to this calculation are the installation costs, financing parameters, and annual energy production. Installation costs vary by region of the country. Table S1 provides the latest 
cost estimates for different regions including the median installation costs as well as the $20^{\text {th }}$ and $80^{\text {th }}$ percentile costs in each region in 2014 , the latest year for which these data are available (David Feldman and Galen Barbose, 2015). We used the median costs for our best estimate, and $20^{\text {th }}$ and $80^{\text {th }}$ percentile costs for our optimistic and pessimistic estimates, respectively. While this model is similar to NREL's System Advisor Model (SAM) (Gilman, 2013), constructing a model outside of the SAM platform allowed comparisons across locations with input parameters that vary by location and allowed for a more robust sensitivity analysis. We assumed that annual operation and maintenance (O\&M) costs are \$21/kW-year (NREL, 2015), and included an additional \$1,500 for inverter replacement in year 15 (Sunrun Inc., 2013). The inverter replacement cost may be an overestimate if in the future the price of inverters decreases more rapidly than it has in the past. However, this assumption does not significantly affect our results.

To model annual energy production, we used the Sandia PV Performance Model, which uses sun-earth geometry, insolation data, and module performance characteristics in order to simulate power output (Sandia National Laboratories, 2013). For each location, we assumed a southfacing PV array with a fixed tilt at an angle equivalent to the latitude for the most year-round solar energy (Del Vecchio, 2009). We assumed a system size of $4 \mathrm{~kW}$ for all locations as this reflects the average size of residential installations and largely avoids oversizing. Note that the median size of residential installations grew to $6 \mathrm{~kW}$ in 2014, however, the installation costs used in the analysis were for 4-6 kW systems. Thus, modeling a $6 \mathrm{~kW}$ system would not benefit from economies of scale and would not change our results (David Feldman and Galen Barbose, 2015). For the base analysis, we used the performance characteristics of the crystalline silicon BP Solar BP3220N Module, as explained in more detail in the SI. We used the I-Power SHO-5.2 
inverter provided in the Sandia Inverter Database that has a power rating of $5.2 \mathrm{~kW}$, appropriate for a $4 \mathrm{~kW}$ system. The insolation data used in this analysis come from the National Solar Radiation Database, which provides typical meteorological year (TMY) data that contain hourly solar radiation values and meteorological elements for 1,011 station locations across the U.S. (excluding territories). These typical meteorological data characterize conditions at each site over longer periods of time and contain actual time-series meteorological measurements and modeled solar values, though some values may result from interpolations where measurements were not available (Wilcox and Marion, 2008). The SI provides mores details about this dataset and Figure S4 provides the spatial distributions of the stations included in the database. Figure S5 shows the annual energy produced from a $4 \mathrm{~kW}$ system with c-Si modules.

Additional parameters in the engineering-economic model include the financing terms, discount rate, and system degradation rate. The most affordable and widely recommended financing mechanism for homeowners wishing to purchase a solar PV system are non tax-deductible loans (Clean Energy Authority, 2013). To model these loans, which unlike home equity loans do not allow for a tax break on the interests paid, we considered nominal interest rates between 4.7$8.4 \%$, depending on the scenario. We also assumed loan terms of up to 20 years to approach the typical 25-year warranty of a solar PV system (Clean Energy Authority, 2013). We used a discount rate of 7\% as recommended by the Office of Management and Budget (2014) and varied it between $0-10 \%$ for sensitivity. Lastly, we assumed the rate at which the module performance declines over time is $3 \%$ during the first year and $0.5 \%$ annually thereafter (“Compare Solar Efficiency Losses Over Time,” 2011; Jordan and Kurtz, 2013). Table 1 summarizes the financial assumptions for each of the scenarios. Note that this paper does not 
include an analysis of the monetized benefits that connectivity to the power system provides to customers who have solar PV systems, nor the cost imposed on the power system from intermittent solar output, which results in more variable system net load. Furthermore, we did not account for the social benefits associated with zero-emissions generating capacity (Siler-Evans et al., 2013).

We calculate the break-even electricity price using the general form:

\section{$B E_{\text {Electricity Price }}$}

$$
=\frac{\sum_{y=0}^{n} \frac{\left(\text { Capital Cost } \times \frac{i_{e}\left(1+i_{e}\right)^{n}}{\left(1+i_{e}\right)^{n}-1}\right)}{(1+D R)^{n}}+\sum_{y=0}^{\text {Lifetime }} \frac{\text { Annual O\&MCost }(y)}{(1+D R)^{y}}}{\sum_{y=0}^{\text {Lifetime }} \frac{\text { Annual Generation }(y)}{(1+D R)^{y}}}
$$

where $i_{e}$ is the effective annual interest rate of the loan, $n$ is the term of the loan in years, and $D R$ is the discount rate. Since loans are compounded monthly but the break-even electricity price equation relies on annual cash flows, the effective annual interest rate is defined as:

$$
i_{e}=\left(1+\frac{r}{m}\right)^{m}-1
$$

where $r$ is the nominal interest rate and $m$ is the number of compounding periods in the year. For this analysis, $m=12$. While different from the traditional definition of LCOE that Joskow (2011) criticizes (provided in the SI), which does not conventionally include financing costs or changes in the capacity factor throughout the years, this equation is similar to what NREL's SAM documentation has termed LCOE (Gilman, 2014). To avoid confusions, we thus refer to this as the break-even electricity price. 
As part of a sensitivity analysis, we explored the effects of existing federal and state subsidies. When including the federal ITC, we assumed that the tax credit is distributed over five years, as per the five-year compliance period (OCC, 2014). A customer may, however, carry the ITC back one year or carry it forward 20 years (OCC, 2014). When using the full ITC in the first year, the break-even electricity price decreases by less than one cent, on average. Most states, however, have a difference in break-even and retail electricity prices greater than one cent, such that using the full ITC in the first year is not critical. On the state level, we considered solar renewable energy certificates (SRECs), rebates, and loan programs as well as state personal tax credits and tax deductions as available from the Database of State Incentives for Renewable \& Efficiency (N.C. Clean Energy Technology Center, 2015). We assume that personal tax credits are distributed evenly over five years, unless the state's program requires a shorter period, in which case we assume the tax credit is used in full during the first year. For tax deductions, we use the state's average household income to determine the annual tax benefit and distribute annually according to the guidelines of the tax deduction. The SI includes details on the subsidies considered in this analysis.

\subsection{Comparison with Current Electricity Prices}

The break-even price of electricity calculated with our engineering-economic model is the lifetime price of electricity that system owners need to receive (or avoid from the grid) in order to reach socket parity. While some residential customers may elect to enter a power purchase agreement (PPA), this financing option is not always allowed (Kollins et al., 2010). Similarly, while a new business model has been developed in California in which companies are leasing solar PV systems to residential customers (Farrell, 2014), this paper focuses on customer-owned 
systems. The break-even electricity prices we estimate can thus allow customers to better compare the options of purchasing or leasing a solar PV system.

Our goal, however, is to identify locations where customer-owned residential solar PV systems have reached socket-parity. In order to identify these locations we thus need information about current electricity prices. We obtained utility price data for the latest year available (2012) from the Open Energy Information (OpenEI) database (Open Energy Information, 2014) and compared them with the break-even electricity price. Since multiple utilities may provide service to the same county, we developed a weighted-average electricity price for each county, based on the total energy sales of each utility across its service territory. Further, these rates are the "bundled" rates provided by OpenEI and are assumed to include generation, transmission, and distribution costs. Figure 1A shows the retail electricity price we derived for locations across the country. For further details about retail price heterogeneity, Figure S6 in the SI shows that differences between highest and lowest electricity prices within each county can be up to about $10 \notin / \mathrm{kWh}$. In addition, Figure S7 shows the highest electricity prices in each county, which are sometimes much higher than the weighted average retail price we used in our analysis. While we did not specifically analyze these outliers, the economics of solar PV improve when displacing higher retail costs.

\subsection{Net Metering}

When a solar PV system produces power that exceeds the owner's simultaneous load, many utilities have net metering programs that credit customers at the residential retail rate for the energy from rooftop solar PV sent to the grid. However, this effectively constitutes a subsidy and 
in the future many utilities are likely to try to compensate producers of surplus power at wholesale prices, which are significantly lower than retail prices. While residential load profiles vary locally and across the U.S., we assumed that $30 \%$ of the annual energy produced by solar PV systems is exported back to the grid, which falls within the $20-40 \%$ range supported by both a study by LBNL as well as by the Solar Energy Industries Association (Naïm Darghouth, 2010; Solar Energy Industries Association, 2015). Thus, in order to account for potential changes in net metering benefits, we performed an additional analysis in which the electricity price we compare to the break-even electricity prices is a weighted average of the local retail rates previously described (weight is 70\%) and the regional average wholesale prices shown in Figure 1B (weight is 30\%) (U.S. Energy Information Administration, 2013).

\subsection{Alternative module technologies}

There have been suggestions that newer module technologies (i.e. thin-film) could perform better than the common crystalline silicon (c-Si) module type under certain climate conditions (Gottschalg et al., 2004; Huld et al., 2010; Matthews et al., 2004). To better understand the effect of using the optimal module type for a given location, we compared the annual energy production from the common crystalline silicon (c-SI) module to various module types, including triple-junction amorphous silicon (3-a-Si), multi-crystalline silicon (mc-Si), Heterojunction with Intrinsic Thin layer silicon (HIT-Si), and cadmium telluride (CdTe) modules. We include these four particular alternative module types because they represent first and secondgeneration solar PV technologies at various levels of commercialization. Since region-specific installation costs for these alternative technologies are unavailable, we calculated the break-even electricity price by parametrically varying the installation costs nationally for each module type to assess differences between module types in economic terms. 


\section{Results and Discussion}

When evaluating the current economics of solar PV without subsidies, we considered pessimistic, best, and optimistic parameters, as defined in Table 1. Figure 2 shows the breakeven electricity prices for installations across the country for these scenarios. Not surprisingly, the break-even electricity price is lowest for states in the Southwest that have high insolation. To put these prices in perspective, Figure 3 shows the difference between the break-even and current retail electricity prices (weighted at the county level as previously described), as well as the cumulative distribution of these differences. Only Hawaii, not shown in the map, achieves statewide socket parity across any scenario due to high retail electricity prices and high insolation. Figure 3D suggests that residential solar PV has yet to reach widespread socket parity when considering customer-owned investments without the use of subsidies, with less than 5\% of locations at parity regardless of the scenario.

\subsection{Sensitivity Analysis}

To better understand the influence of the variables that drive the break-even electricity price, we used the best estimate as the base case and individually varied the nominal interest rate and loan term $(0-8.4 \%, 5-30$ years $)$, installation cost $\left(20^{\text {th }}-80^{\text {th }}\right.$ percentile $)$, discount rate $(0-10 \%)$, and maintenance costs (annual and inverter replacement). No additional states achieve widespread socket parity when changing any one parameter between the upper and lower bounds. When using a $0 \%$ nominal interest rate (a highly subsidized loan), 10-20\% of locations within Alaska, California, New Mexico, and New York achieved socket parity. It may seem surprising that parts 
of Alaska would reach parity, but this is primarily driven by retail electricity prices exceeding 40 $\notin / \mathrm{kWh}$.

\subsection{Effect of Subsidies}

In the best estimate scenario, only Hawaii has achieved socket parity. Even in the optimistic scenario of $20^{\text {th }}$ percentile 2014 installation costs financed with a 20 -year, $4.7 \%$ loan, widespread socket parity has not been achieved (only 3\% of locations nationwide have achieved socket parity). Given that widespread parity at current installation costs without subsidies is unlikely, we considered the economics of these solar PV systems with the federal ITC alone, as well as the combination of the federal ITC and existing state subsidies. In Figure 4 the difference in breakeven and retail electricity prices for these scenarios shows that federal and state subsidies improve the economic viability of residential PV systems in several states (some of which are subsidized more than what is necessary to reach socket parity), yet widespread parity is still not achieved. Further, if the federal ITC does in fact expire at the end of 2016 for residential customers and state and local subsidies remain uncertain, it may take longer to achieve widespread socket parity.

\subsection{The SunShot Initiative}

The Department of Energy's SunShot Initiative calls for installation costs for residential systems of $\$ 1.5 / \mathrm{W}$ by 2020 (Ardani et al., 2013). This target is significantly lower than the system costs in our base case scenarios. The fact that residential installed costs in Germany averaged $\$ 2.13 / \mathrm{W}$ in 2013 (David Feldman and Galen Barbose, 2015) suggests that the SunShot target may be feasible. Figure 5 shows the difference between break-even and retail electricity prices with 
installation costs of $\$ 4.5 / \mathrm{W}$ (2014 national average for 4-6 kW systems), the 2013 Germany benchmark, and the SunShot Initiative target. In addition to locations in the Southwest, lower installation costs bring locations in the Northeast to socket parity due to high retail electricity prices. Meanwhile, Florida, nicknamed the "sunshine state", barely reaches socket parity with current electricity prices, even at the SunShot target costs.

To examine how the financial assumptions in our model affect the break-even electricity price of the system under the SunShot target installation cost, we perform a sensitivity analysis varying the key assumptions in our model while assuming a uniform installation cost of $\$ 1.5 / \mathrm{W}$ across the country. The model was most sensitive to the interest rate, discount rate, and annual maintenance costs, as seen in Figure 6. Of these variables, the homeowner only has control of the annual maintenance costs and interest rate when financing a system. The annual maintenance cost was varied between $\$ 84$ and $\$ 0$ (note that inverter replacement costs are still included at year 15). Thus, if a homeowner can self-provide all required maintenance (washing if needed and cleaning debris off panels), then the economics of a solar PV investment can be improved considerably: $78 \%$ of sites in the best case scenario would achieve socket parity without other subsidies, while $98 \%$ would achieve socket parity if state and federal subsidies continued to be available. Similarly, securing a loan with a low interest rate is very valuable. The firm SolarCity has recognized the business opportunity for providing loans with low interest rates with their MyPower solar loans that offer interest rates as low as $4.5 \%$ to customers in select states (SolarCity, 2014). As we progress towards the SunShot Initiative's 2020 goal, financing at low rates can significantly improve the economics of a residential solar PV investment, especially if government subsidies are not available. 


\subsection{Net Metering and Displaced Costs of Energy}

As previously noted, the continuation of net metering programs is uncertain in the future as utilities may compensate solar PV owners for any excess generation only at the wholesale electricity prices. To account for this possibility, we compared the break-even price of electricity for the systems with a weighted average of retail and wholesale electricity prices, assuming $30 \%$ of electricity produced by the residential solar PV systems is sold to the grid. Figure 7 shows the results of this comparison. Even with SunShot installation costs, if $30 \%$ of electricity produced by the solar PV system were sold to the grid at wholesale prices, most of the United States would not achieve socket parity. This highlights the effect that net metering has on the economics of solar PV for residential customers as well as the importance of avoiding oversizing the solar PV system relative to a customer's load.

In addition to net metering, there are some utilities (particularly those in California) that implement tiered pricing for residential customers. For customers with high levels of energy consumption, a solar PV system can displace electricity at rates much higher than the average retail electricity price. Similarly, net metering with time-of-use rate tariffs can provide an opportunity to shift consumption to off-peak times and receive credit for generation at peak rates. This has the potential to improve the economics for solar PV, but is highly dependent on the customer's load as well as the structure of the tariff.

\subsection{Alternative Module Types}

While c-Si is the most common PV module type, a number of other solar technologies may be viable in the future. These technologies have different performance characteristics that, under 
some conditions, may allow them to produce more energy than c-Si modules. Figure 8 shows the differences in annual energy production from a c-Si module and four other module types, each scaled to $4 \mathrm{~kW}$. This figure suggests that there are regional differences in the annual energy production of the alternative module types, probably arising in part from their varying temperature sensitivities. Generally, higher temperatures result in decreased module performance. Note that 3-a-Si, and HIT-Si modules consistently outperformed c-Si modules, with the differences in annual output increasing with higher temperatures (SANYO, 2003). The mc-Si module performed similarly to the c-Si module as the difference in annual output between the two modules is negligible. On the other hand, CdTe modules always underperform the c-Si module, however, the gaps in performance decrease as temperatures increases. Because these alternative modules are at different stages of development and deployment, their competitive position may change in the future and there may be additional benefits not captured in our model. For example, alternative modules may produce less variable power; or their production may be more coincident with daily peak demand.

Because costs of these modules are less clear, we estimate break-even electricity prices for these systems at different installation costs. Figure 9 shows the difference in break-even electricity prices between the c-Si module and the four other module types if each module cost $\$ 4 / \mathrm{W}$. Positive (red) numbers indicate that the alternative module is more cost effective than the c-Si module.

\section{Conclusions and Policy Implications}

In summary, our results suggest that socket parity without subsidies has not yet become a reality in the lower 48 states. For residential solar systems to reach socket parity, continued installation- 
cost reductions are critical, along with the availability of low-interest loans and the ability to reduce or eliminate annual maintenance costs. Further, socket parity is highly dependent on how much, and at what rate, excess electricity is sold back to the grid. While net metering programs can improve the economics of residential solar PV, they represent a financial burden for most utilities because they can purchase electricity at lower prices in the wholesale market, and because utilities must continue to cover the operation and maintenance costs of the distribution systems to which solar PV systems are connected (Kind, 2013).

When examining potential benefits of using less common solar PV module technologies, we found that the ideal module type varies by climate, in part due to varying temperature sensitivities. Because ours is an engineering-economic analysis performed from the perspective of the homeowner, it does not consider potential societal benefits of increased solar PV penetration. Similarly, this assessment does not account for the value of reducing dependencies on foreign and local fuels that historically have been subject to price volatility. Together these benefits may provide sufficient incentive for maintaining at least some government subsidies.

Until the SunShot cost targets are achieved, continued subsidies can support the growth needed to meet state and federal goals of increased renewable generation. As shown in Figure 4, subsidies have enabled some states to achieve socket parity that would not otherwise occur with current installed costs. However, these state subsidies may yield varying amounts of public benefit. If the goal is to encourage more installations, smaller subsidies in states closer to parity may achieve that goal more efficiently than subsidizing installations in states not close to parity. Similarly, if the goal is to achieve the greatest public health benefits by reducing air emissions from the power system, then subsidies in states with a "dirtier" electricity mix may provide more benefit than subsidies in states with a "cleaner" electricity mix (Siler-Evans et al., 2013). Given 
different goals, it may be necessary to reallocate subsidies instead of providing the same level of support throughout every location, as the ITC does. Once the SunShot cost target is reached, policy-makers should consider what timing is most appropriate for the reduction or elimination of additional financial support for solar PV systems. The analysis in this paper should be helpful in informing that decision-making process.

\section{ACKNOWLEDGMENTS}

This work was supported by academic funds from the Department of Engineering and Public Policy, by the program for Graduate Assistance in Areas of National Need (GAANN) of the U.S. Department of Education, by the Department of Energy under Awards DE-OE0000300 and DEOE0000204, by the NSF center for Climate and Energy Decision Making Center (CEDM) (SES0949710), and by the Carnegie Mellon Electricity Industry Center (CEIC). Results and conclusions are the sole responsibility of the authors and may not represent the views of the funding sources.

\section{References}

Ardani, K., Seif, D., Margolis, R., Morris, J., Davidson, C., Truitt, S., Torbert, R., 2013. NonHardware ("Soft") Cost-Reduction Roadmap for Residential and Small Commercial Solar Photovoltaics, 2013-2020. doi:10.2172/1096122

Barbose, G., Weaver, S., Darghouth, N., 2014. Tracking the Sun VII: An Historical Summary of the Installed Price of Photovoltaics in the United States from 1998 to 2013.

Bazilian, M., Onyeji, I., Liebreich, M., MacGill, I., Chase, J., Shah, J., Gielen, D., Arent, D., Landfear, D., Zhengrong, S., 2013. Re-considering the economics of photovoltaic power. Renewable Energy 53, 329-338. doi:10.1016/j.renene.2012.11.029

Bhandari, R., Stadler, I., 2009. Grid parity analysis of solar photovoltaic systems in Germany using experience curves. Solar Energy 83, 1634-1644. doi:10.1016/j.solener.2009.06.001

Branker, K., Pathak, M., Pearce, J.M., 2011. A review of solar photovoltaic levelized cost of electricity. Renewable and Sustainable Energy Reviews.

Breyer, C., Gerlach, A., 2013. Global overview on grid $\square$ parity. Progress in Photovoltaics: Research and Applications 21, 121-136. doi:10.1002/pip.1254

BusinessGreen.com staff, 2009. Solar giants predict grid parity in five years [WWW Document]. URL http://www.businessgreen.com/bg/news/1807448/solar-giants-predict-grid-parity (accessed 12.24.14).

Clean Energy Authority, 2013. How Long is a Standard Solar PV Warranty? [WWW Document]. CleanEnergyAuthority.com. URL http://www.cleanenergyauthority.com/solarenergy-resources/solar-pv-warranty (accessed 11.15.13).

Committee on Health, Environmental, and Other External Costs and Benefits of Energy 
Production and Consumption, National Research Council, 2010. Hidden Costs of Energy. National Academies Press.

Compare Solar Efficiency Losses Over Time, 2011. Compare Solar Efficiency Losses Over Time 1-7.

Database of State Incentives for Renewables \& Efficiency, 2015. Net Metering [WWW Document]. DSIRE Solar. URL http://www.dsireusa.org/solar/solarpolicyguide/?id=17 (accessed 1.13.15).

Database of State Incentives for Renewables \& Efficiency, 2013. Financial Incentives for Solar PV 1-1.

David Feldman, R.M.D.C.R.F.A.C.D.N., Galen Barbose, M.B.J.S.A.R.W.L.B.N.L., 2015. Photovoltaic System Pricing Trends: Historical, Recent, and Near-Term Projections, 2015 Edition (Presentation), Sunshot, U.S. Department of Energy (DOE), in:. pp. 1-35.

Del Vecchio, D., 2009. Optimizing a PV Array with Orientation \& Tilt. Home Power.

Durkay, J., 2014. Net Metering: Policy Overview and State Legislative Updates [WWW Document]. National Conference of State Legislatures. URL (accessed 9.15.15).

Farrell, J., 2014. High Cost Of The Solar Middleman | CleanTechnica [WWW Document]. cleantechnica.com. URL (accessed 5.13.14).

Farrell, J., 2012. Rooftop revolution. Institute for Local Self-Reliance.

Gilman, P., 2014. System Advisor Model (SAM). NREL.

Gilman, P., 2013. System Advisor Model (SAM) [WWW Document]. URL (accessed 11.15.13).

Gottschalg, R., Betts, T.R., Williams, S.R., Sauter, D., 2004. A critical appraisal of the factors affecting energy production from amorphous silicon photovoltaic arrays in a maritime climate. Solar Energy.

H-0702 As Passed by Both House and Senate, 2014. H-0702 As Passed by Both House and Senate.

Hetter, J., Gelman, R., Bird, L., 2014. Status of Net Metering: Assessing the Potential to Reach Program Caps.

Honeyman, C., Litvak, N., Kann, S., Mehta, S., Shiao, M.J., Jones, J., Kimbis, T., Baca, J., Rumery, S., Holm, A., 2014. U.S. Solar Market Insight Report Q2 2014 Executive Summary [WWW Document]. Solar Energy Industries Association. URL (accessed 12.1.14).

Huld, T., Gottschalg, R., Beyer, H.G., Topič, M., 2010. Mapping the performance of PV modules, effects of module type and data averaging. Solar Energy 84, 324-338. doi:10.1016/j.solener.2009.12.002

Jordan, D.C., Kurtz, S.R., 2013. Photovoltaic Degradation Rates - an Analytical Review. Progress in Photovoltaics: Research and Applications 21, 12-29. doi:10.1002/pip.1182

Joskow, P.L., 2011. Comparing the Costs of Intermittent and Dispatchable Electricity Generating Technologies. The American Economic Review 101, 238-241. doi:10.2307/29783746?ref=no-X-route:210c456b151ae633e04afd33145ec44a

Kann, S., Mehta, S., Shiao, M.J., Krulewitz, A., Campbell, C., Honeyman, C., Litvak, N., Baca, J., Lent, W., Rumery, S., 2013. U.S. Solar Market Insight Report Q1 2013 Executive Summary [WWW Document]. URL (accessed 12.1.14).

Kann, S., Shiao, M.J., Mehta, S., Honeyman, C., Litvak, N., Jones, J., Kimbis, T., Baca, J., Rumery, S., Holm, A., 2014. Solar Market Insight Report 2014 Q3 [WWW Document]. Solar Energy Industries Association. URL http://www.seia.org/research-resources/solarmarket-insight-report-2014-q3 (accessed 1.20.15).

Kimbis, T., Fenn, S., Baca, J., Lent, W., Rumery, S., Hernandez, M., Kann, S., Mehta, S., Shiao, 
M.J., Campbell, C., 2012. U.S. Solar Market Insight Report Q1 2012 Executive Summary [WWW Document]. Solar Energy Industries Association. URL (accessed 12.1.14).

Kollins, K., Speer, B., Cory, K.S., 2010. Solar PV Project Financing: Regulatory and Legislative Challenges for Third-Party PPA System Owners.

Matthews, H.S., Cicas, G., Aguirre, J.L., 2004. Economic and Environmental Evaluation of Residential Fixed Solar Photovoltaic Systems in the United States. Journal of infrastructure systems 10, 105-110. doi:10.1061/(ASCE)1076-0342(2004)10:3(105)

N.C. Clean Energy Technology Center, 2015. Database of State Incentives for Renewables \& Efficiency ${ }^{\circledR}$ [WWW Document]. DSIRE. URL http://www.dsireusa.org (accessed 5.15.15).

Naïm Darghouth, G.B.R.W., 2010. The Impact of Rate Design and Net Metering on the Bill Savings from Distributed PV for Residential Customers in California. Lawrence Berkeley National Laboratory 1-62.

NREL, 2015. Distributed Generation Renewable Energy Estimate of Costs [WWW Document]. URL http://www.nrel.gov/analysis/tech_lcoe_re_cost_est.html (accessed 9.25.15).

OCC, 2014. Public Welfare Investments in Solar Energy Facilities Using Renewable Energy Investment Tax Credit 1-9.

Open Energy Information, 2014. U.S. Utility Rate Database.

Parkinson, G., 2014. Solar Grid Parity In All 50 US States By 2016, Predicts Deutsche Bank [WWW Document]. cleantechnica.com. URL http://cleantechnica.com/2014/10/29/solargrid-parity-us-states-2016-says-deutsche-bank/ (accessed 12.24.14).

Perea, Bonilla, Buchanan, Correa, Daly, Eggman, Garcia, Gray, Pan, 2013. Assembly Bill No. 327.

Kind, Peter. Disruptive Challenges. Edison Electric Institute, 2013. Print.

Reichelstein, S., Yorston, M., 2013. The prospects for cost competitive solar PV power. Energy Policy 55, 117-127. doi:10.1016/j.enpol.2012.11.003

Renewable Portfolio Standard Policies [WWW Document], 2015. Renewable Portfolio Standard Policies [WWW Document]. DSIRE. URL (accessed 9.25.15).

Residential Clean Energy Grant Program [WWW Document], 2015. Residential Clean Energy Grant Program [WWW Document]. DSIRE. URL (accessed 9.14.15).

Richard, M.G., 2014. Game-changer: Rooftop solar will be at grid parity in all 50 U.S. states by 2016 : TreeHugger [WWW Document]. treehugger.com. URL (accessed 12.24.14).

Sandia National Laboratories, 2013. PV Performance Modeling Collaborative.

SANYO, 2003. SANYO HIT Photovoltaic Module HIP-G751BA2 (167W) Specification Sheet. Shah, V., Booream-Phelps, J., 2014. Initiating Coverage with a BUY. Deutsche Bank Markets Research 1-44.

Shahan, C., 2014. Residential Solar Cheaper Than Grid Electricity In 25 States By 2015, Utility CEO States [WWW Document]. cleantechnica.com. URL $<$ http://cleantechnica.com/2014/07/01/residential-solar-cheaper-grid-electricity-25-states/> (accessed 11.16.14).

Siler-Evans, K., Azevedo, I., Morgan, M.G., Apt, J., 2013. Regional variations in the health, environmental, and climate benefits of wind and solar generation. PNAS 110, 11768-11773. doi:10.1073/pnas. 1221978110

Solar Energy Industries Association, 2015. Issues \& Policies [WWW Document]. URL http://www.seia.org/policy/distributed-solar/net-metering (accessed 1.10.15).

Solar Energy Systems Tax Credit (Personal) [WWW Document], 2015. Solar Energy Systems Tax Credit (Personal) [WWW Document]. DSIRE. URL (accessed 9.14.15). 
SolarCity, 2014. SolarCity Introduces MyPower,a First-of-its-Kind Solar Loan Paid Back by the Sun [WWW Document]. URL http://www.solarcity.com/newsroom/press/solarcityintroduces-mypower-first-its-kind-solar-loan-paid-back-sun (accessed 12.23.14).

Sunrun Inc., 2013. Cost of Solar Power [WWW Document]. sunrun.com. URL http://www.sunrun.com/solar-lease/cost-of-solar/ (accessed 12.29.13).

U.S. Energy Information Administration, 2014. Annual Electric Generator Report.

U.S. Energy Information Administration, 2013. Wholesale electricity prices rose across the United States 1-2.

Wilcox, S., Marion, W., 2008. Users manual for TMY3 data sets. 
Table 1: Scenarios for evaluating current economic viability of rooftop solar PV.

\begin{tabular}{|l|l|l|l|}
\hline Variable & Pessimistic & Best & Optimistic \\
\hline Estimate & Estimate & Estimate \\
\hline Installation Cost $(\$ / W)$ & $\begin{array}{l}80^{\text {th }} \text { Percentile } \\
\text { of 2014 Costs in } \\
\text { Table S1 }\end{array}$ & $\begin{array}{l}\text { Median of 2014 } \\
\text { Costs in Table S1 }\end{array}$ & $\begin{array}{l}20^{\text {th }} \text { Percentile of } \\
\text { Table S1 }\end{array}$ \\
\hline Nominal Loan Interest Rate & $8.4 \%$ & $6.5 \%$ & $4.7 \%$ \\
\hline Loan Term (years) & 5 & 15 & 20 \\
\hline
\end{tabular}


A

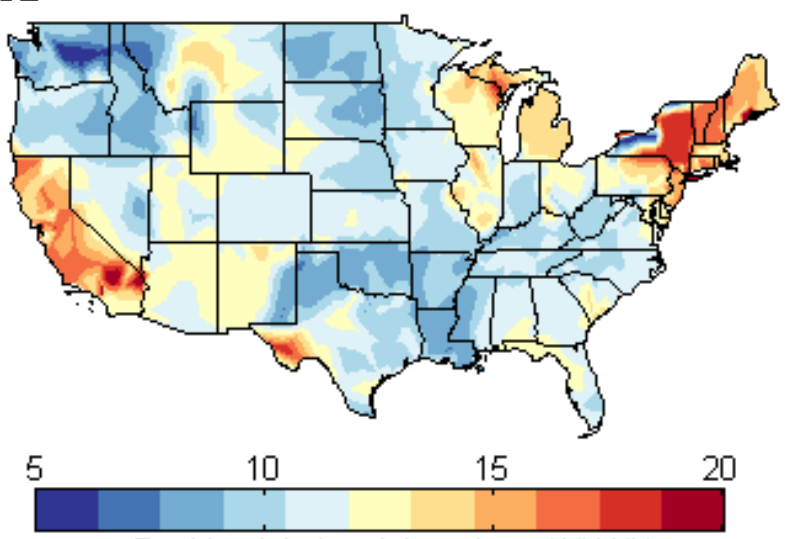

Residential electricity prices ( $\phi / \mathrm{kWh})$
B
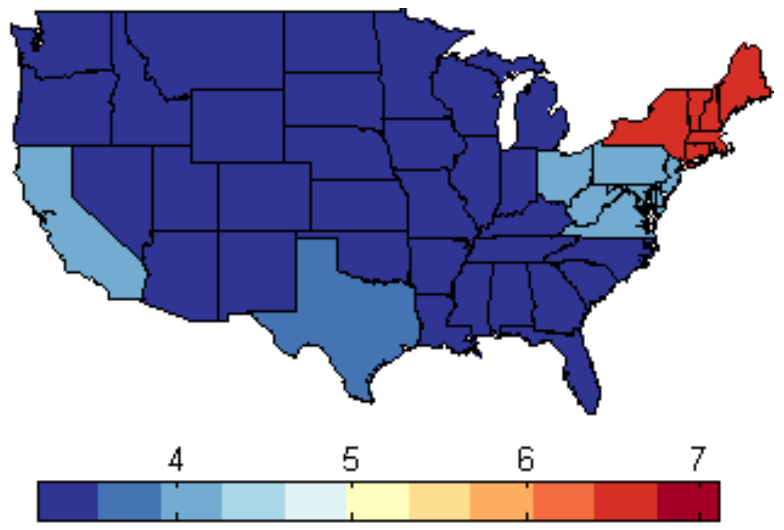

Wholesale electricity price ( $(\mathrm{k} / \mathrm{Wh})$

Figure 1: Residential (A) and wholesale (B) electricity prices used for comparison with estimated breakeven electricity prices. 


\section{B}
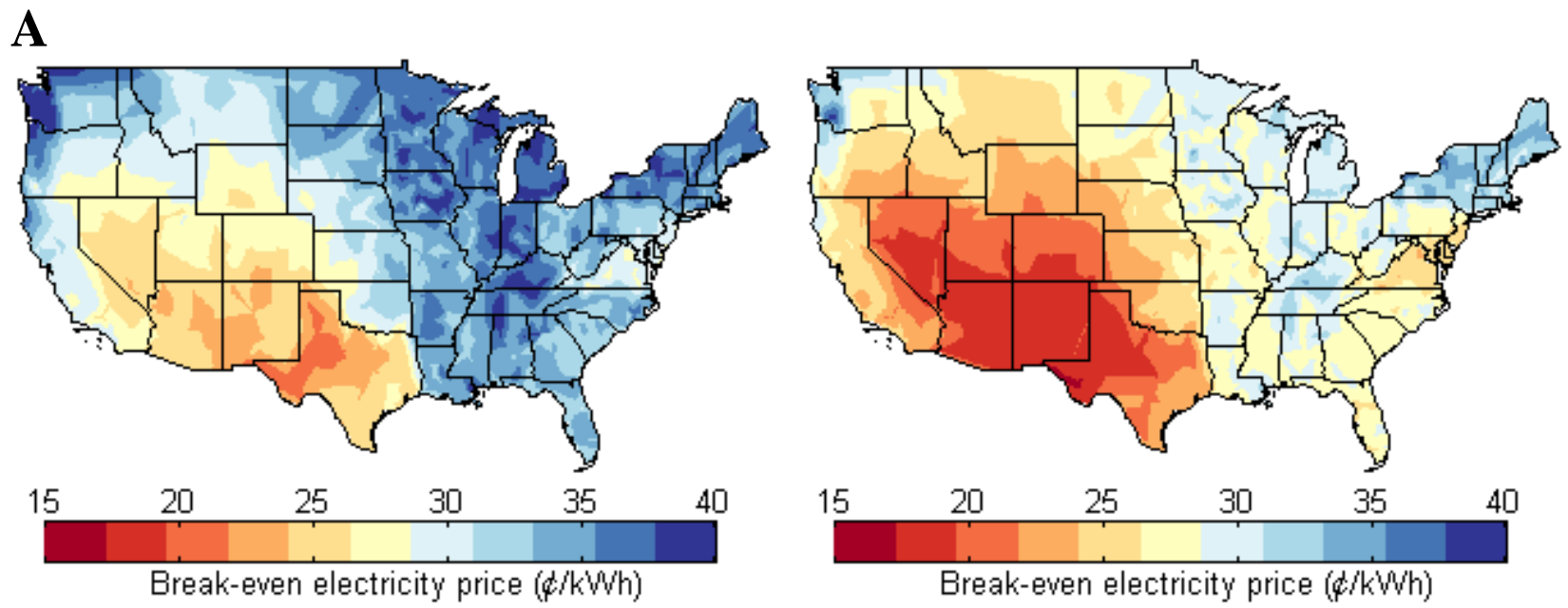

C

D
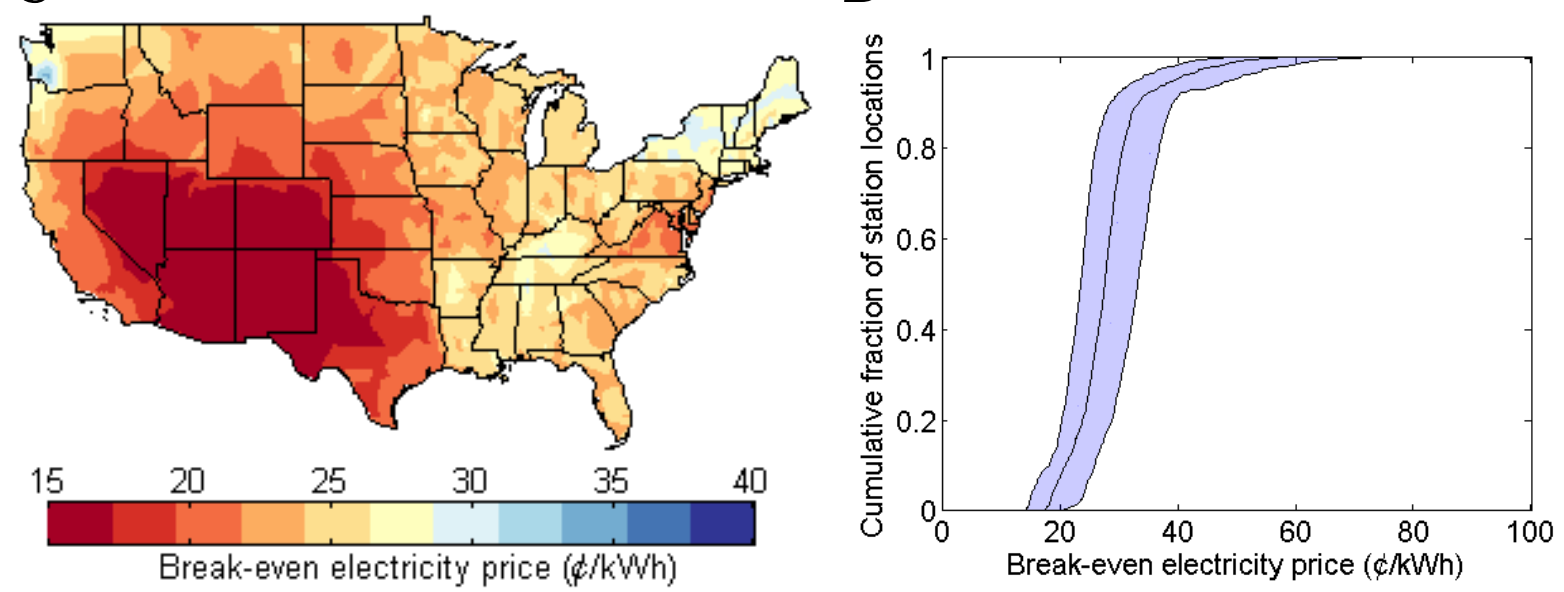

Figure 2: Pessimistic (A), Best (B), and Optimistic (C) break-even electricity prices for a $4 \mathrm{~kW}$ system as well as the cumulative distribution of these prices (D). The cumulative distribution shows the break-even electricity prices for the pessimistic estimate (right-most line), best estimate (middle line), and optimistic estimate (left-most line). These graphs (and later graphs) contain coloring spills across state borders that are an artifact of the smoothing algorithm used over the more than 1,000 sites in this analysis. 
A
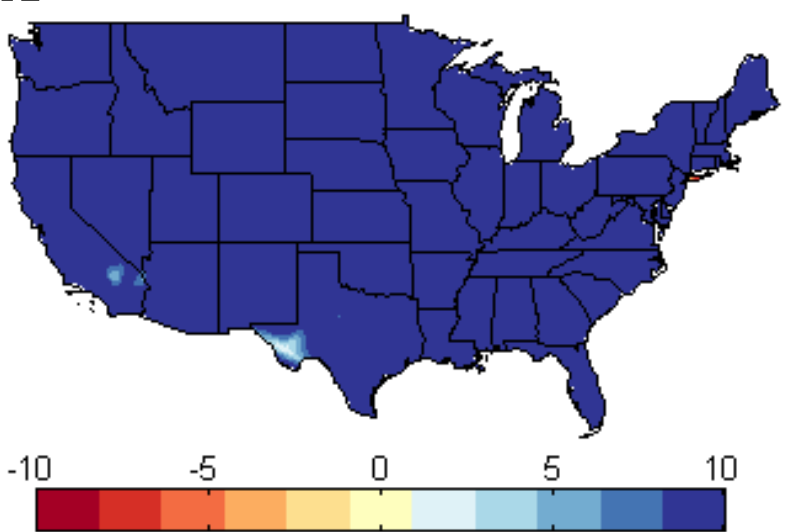

Break-even minus retail price of electricity ( $/ \mathrm{kW} / \mathrm{h})$

C

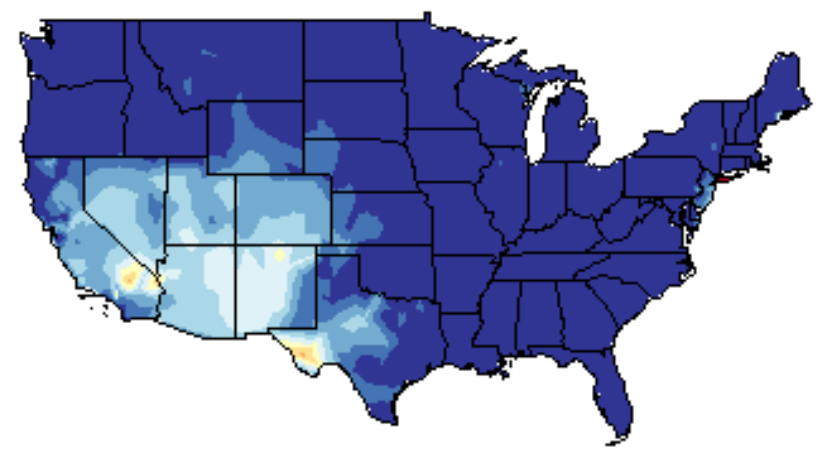

$-10$

$-5$

\section{0}

5

Break-even minus retail price of electricity ( $\phi / k \mathrm{~W} / \mathrm{h})$
B

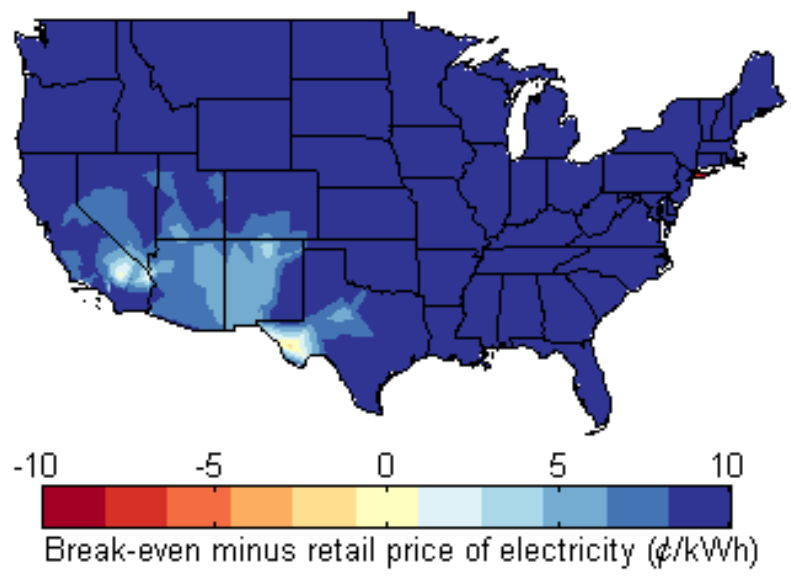

D

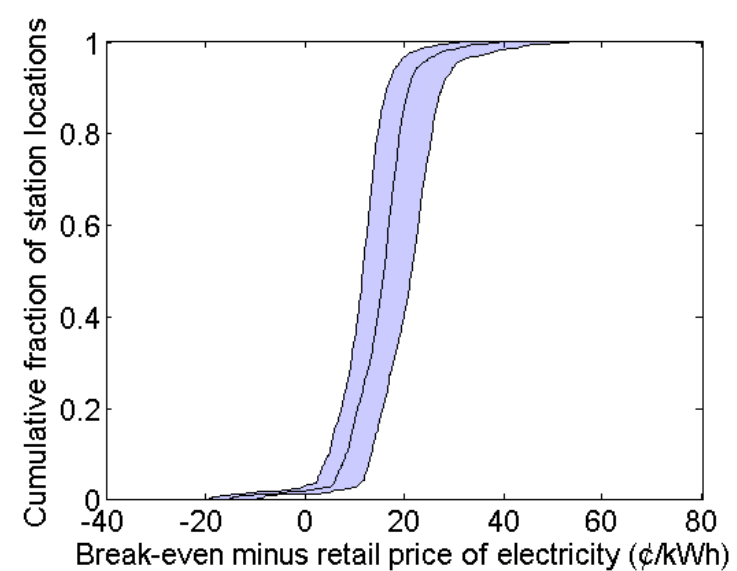

Figure 3: Pessimistic (A), Best (B), and Optimistic (C) estimates of the difference between break-even and current retail electricity prices as well as the cumulative distribution of these differences (D). Positive numbers reflect how far away a location is from reaching socket parity, while negative numbers are locations that have already reached socket parity. The cumulative distribution shows the difference between break-even and current retail electricity prices for the pessimistic estimate (right-most line), best estimate (middle line), and optimistic estimate (left-most line). 
A
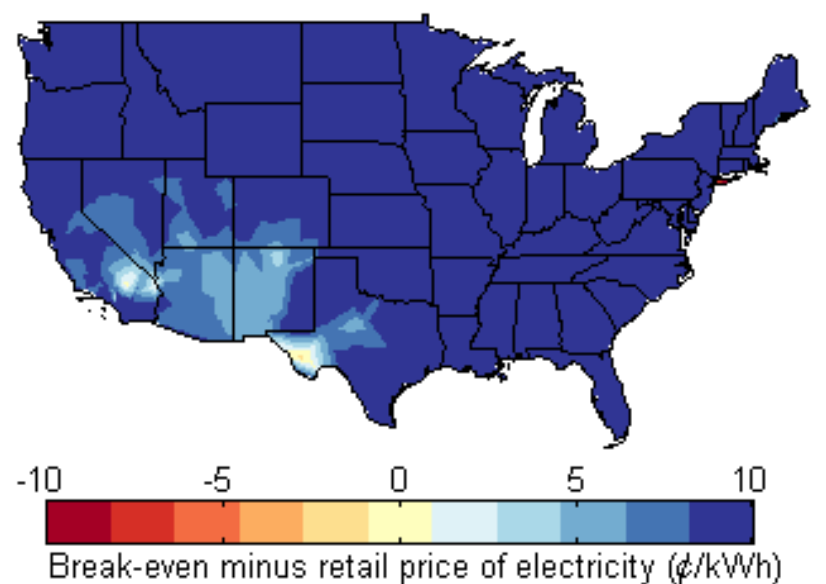

C

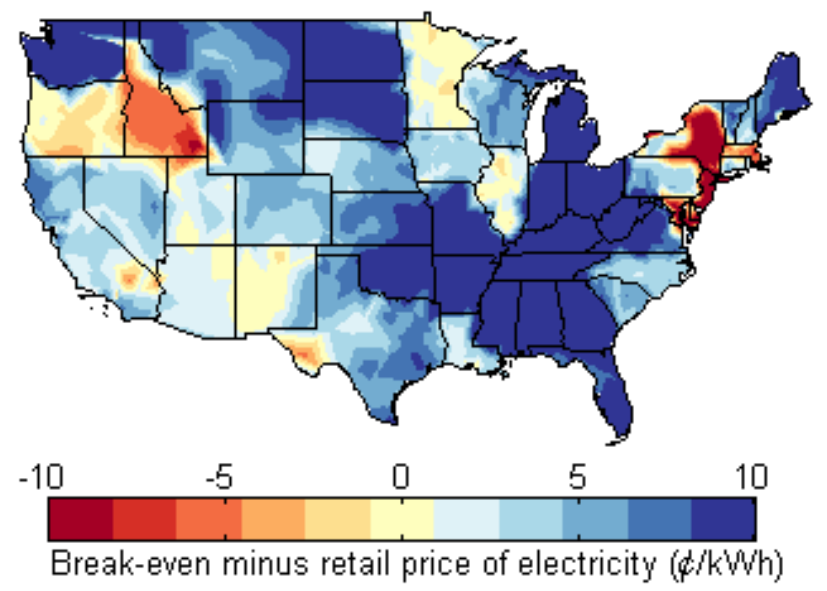

B

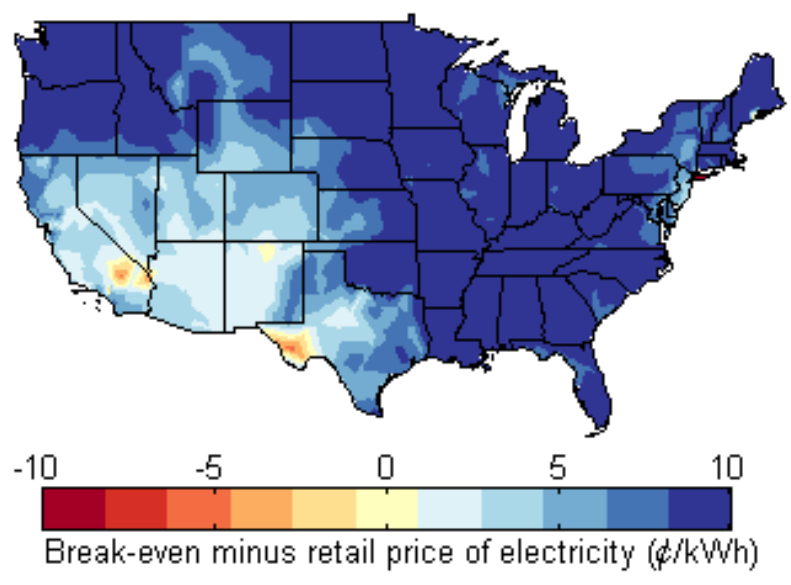

D

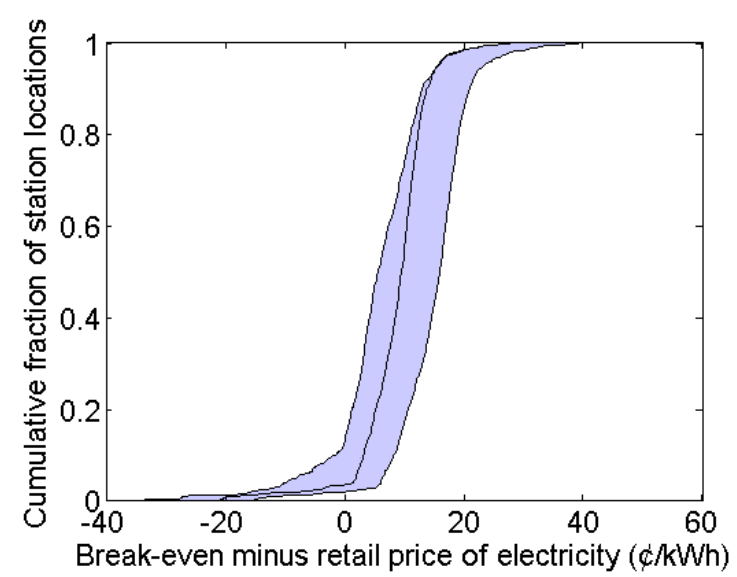

Figure 4: Difference between break-even and retail electricity prices for the best estimate scenario without subsidies (A) with the federal ITC (B), with the combination of the federal ITC and state subsidies (C), and a cumulative distribution of the break-even electricity prices for all locations in the model (D) without subsidies (right-most line), with federal ITC (middle line), and with both the federal ITC and state subsidies (left-most line). 
A
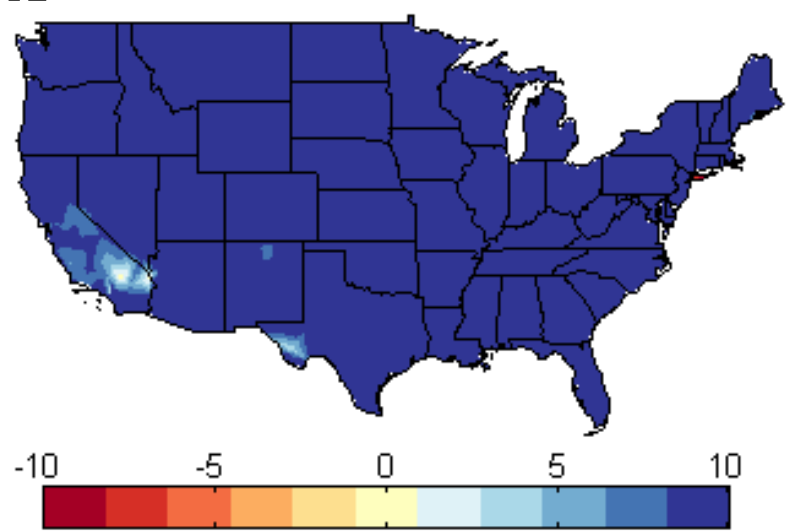

Break-even minus retail price of electricity ( $/ \mathrm{kW} / \mathrm{W}$ )

C
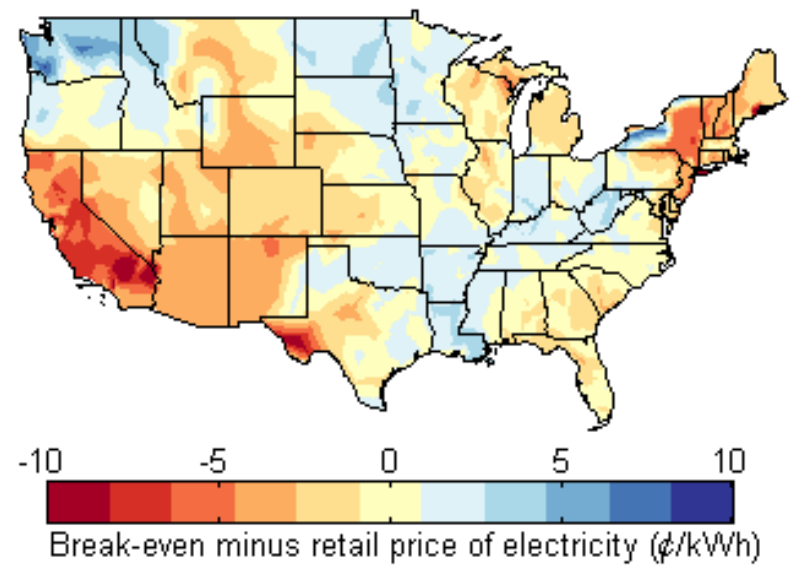

B
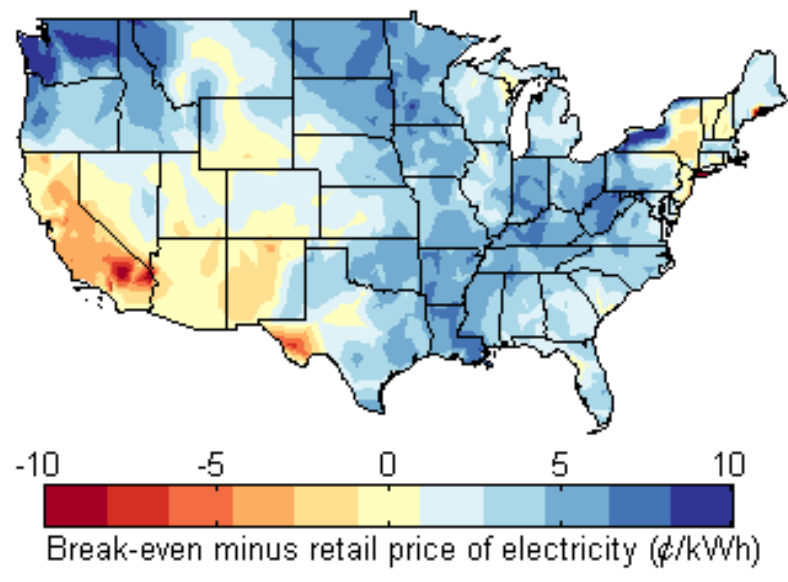

D

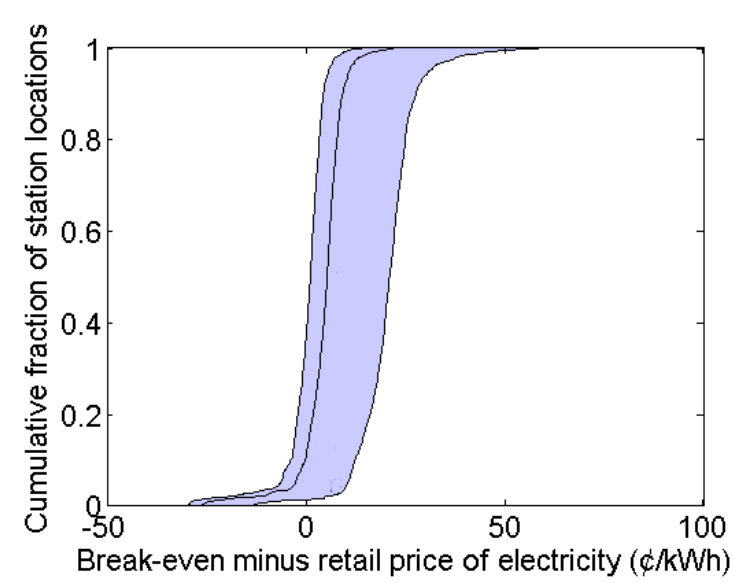

Figure 5: Difference in break-even and retail electricity prices for the best estimate scenario for (A) 2014 national average installed costs of $\$ 4.5 / \mathrm{W}$, (B) 2013 German average of $\$ 2.13 / \mathrm{W}$, (C) SunShot Initiative goal of $\$ 1.5 / \mathrm{W}$, and (D) a cumulative distribution of each for all locations in the model at $\$ 4.5 / \mathrm{W}$ (rightmost line), at $\$ 2.13 / \mathrm{W}$ (middle line), and at $\$ 1.5 / \mathrm{W}$ (left-most line). 


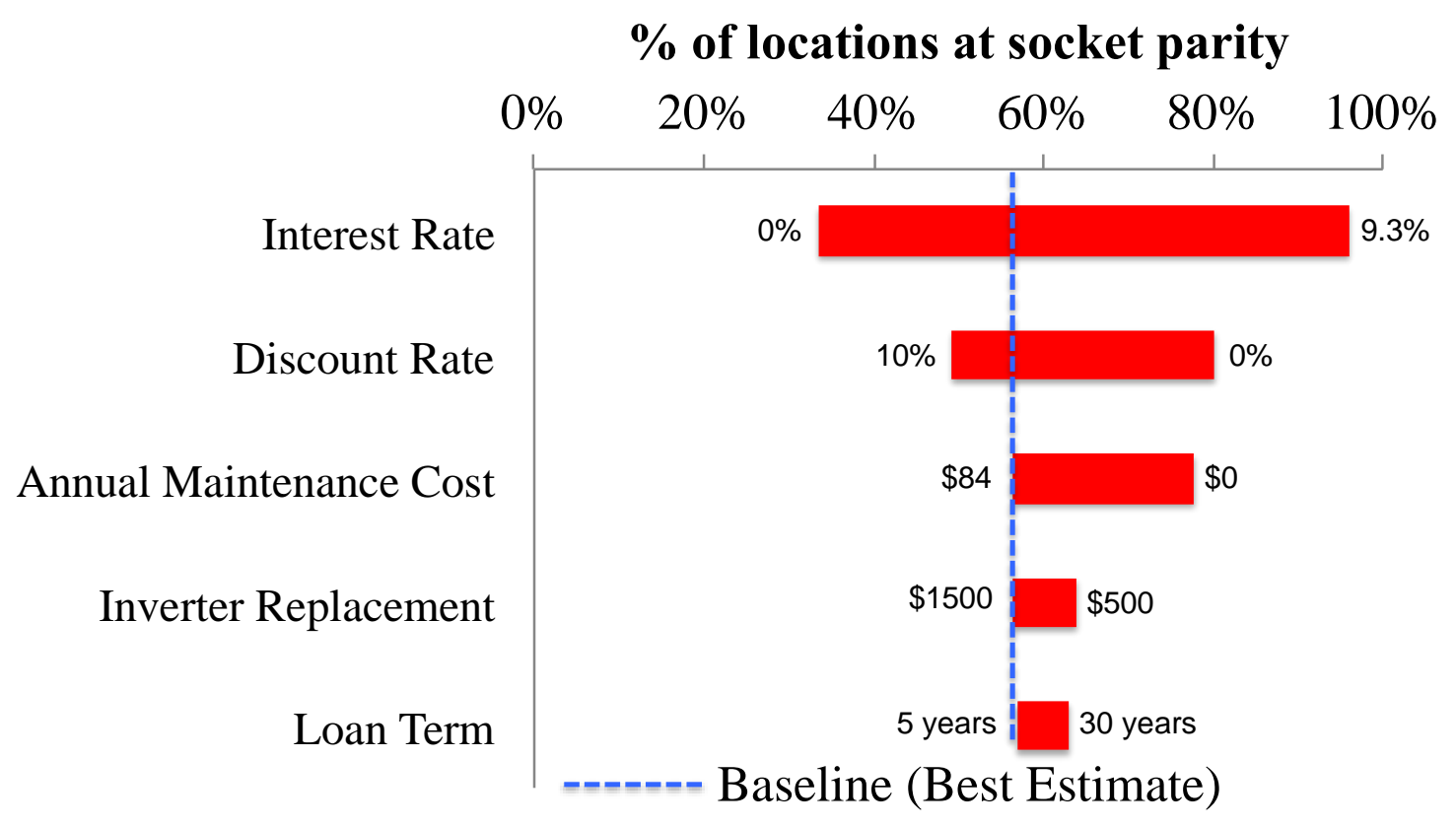

Figure 6: Percentage of stations at socket parity in sensitivity analysis using the best estimate scenario as the baseline and the SunShot Initiative's 2020 residential installed cost target of $\$ 1.5 / \mathrm{W}$. 
A
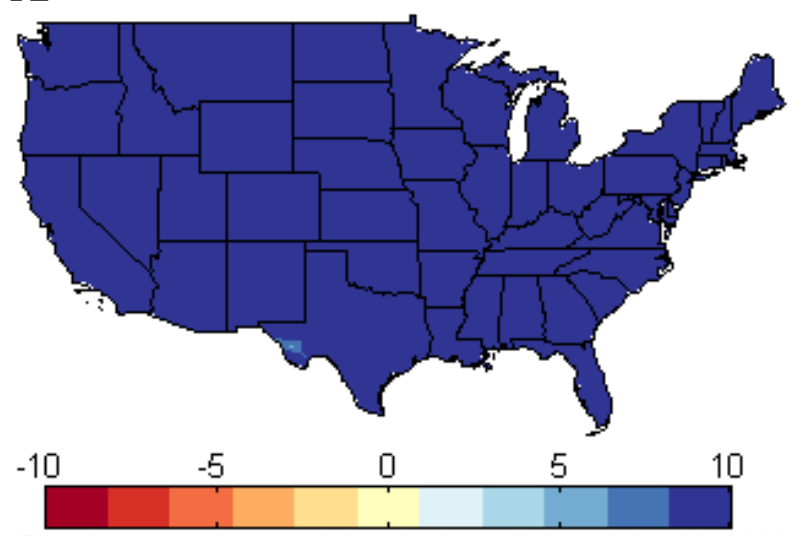

Break-even minus weighted price of electricity $(\phi / k W h)$

C
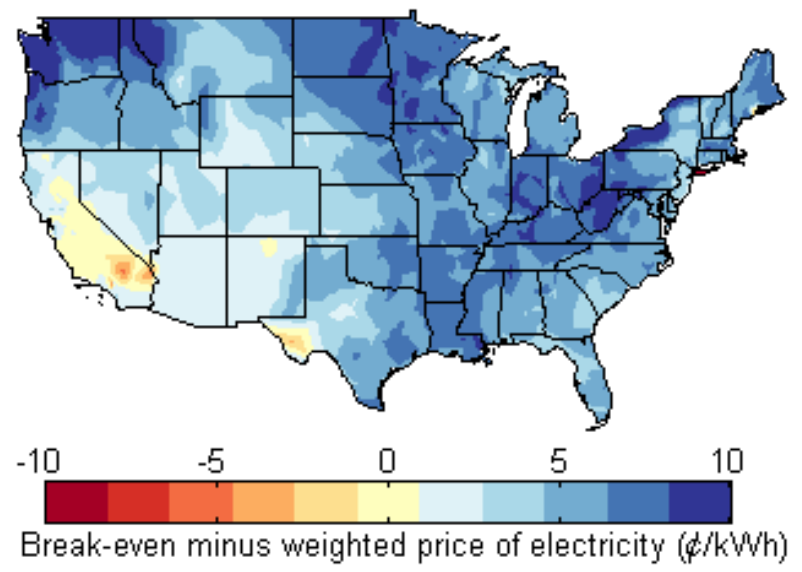

B

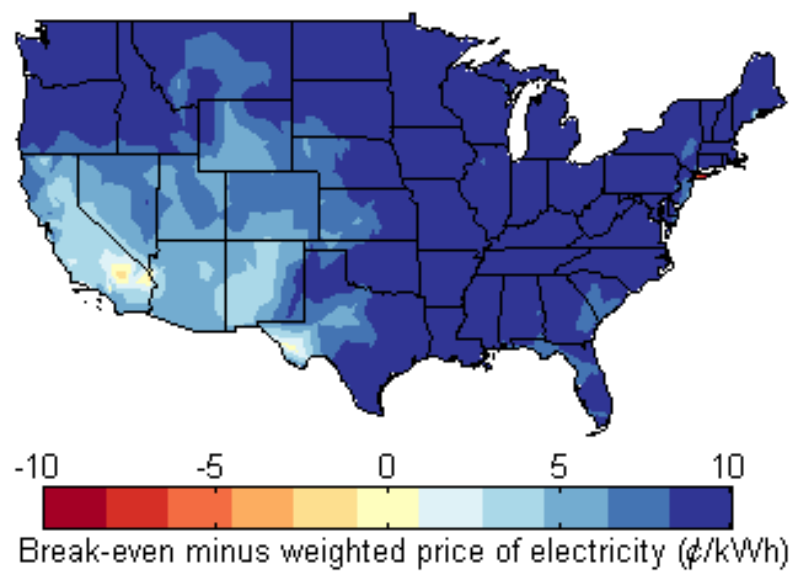

D

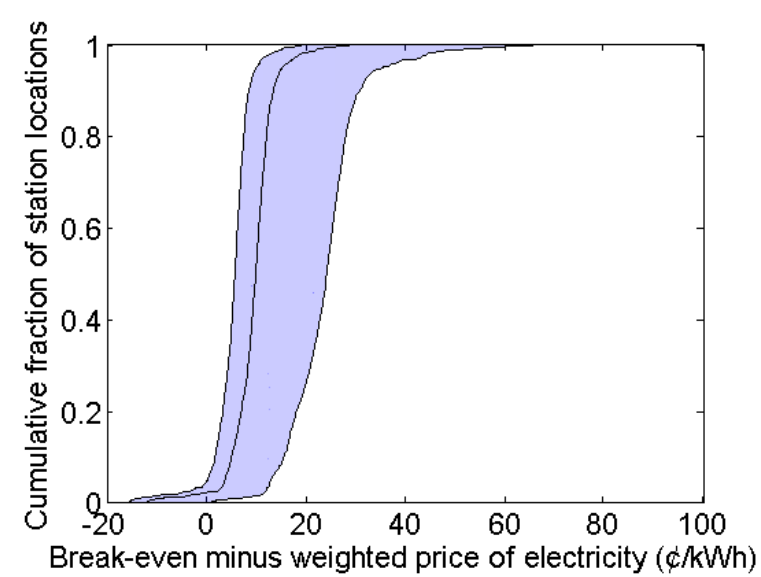

Figure 7: Difference in break-even and weighted (retail/wholesale) electricity prices for the best estimate scenario for (A) current installed costs (B) 2013 German average of $\$ 2.13 / \mathrm{W}$, (C) SunShot Initiative goal of $\$ 1.5 / \mathrm{W}$, and (D) a cumulative distribution of each for all locations in the model at current installed costs (right-most line), at \$2.13/W (middle line), and at \$1.5/W (left-most line). 
3-a-Si

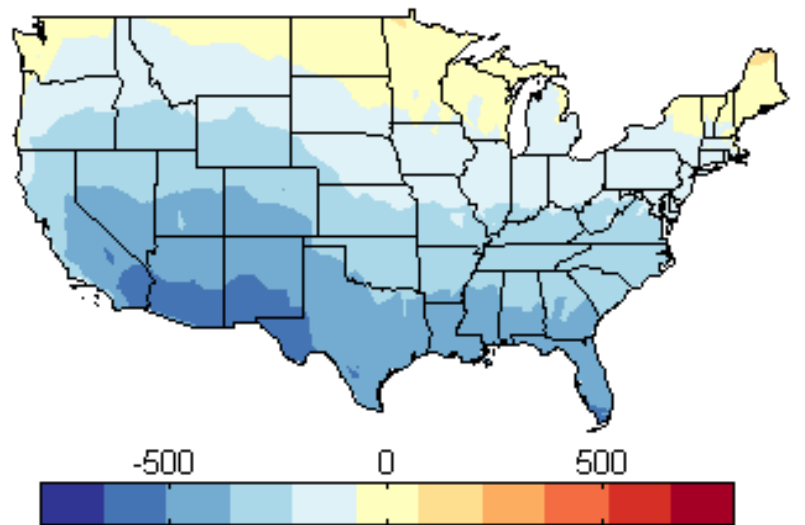

Difference in Annual Energy Produced ( $k$ Wh)

HIT-Si

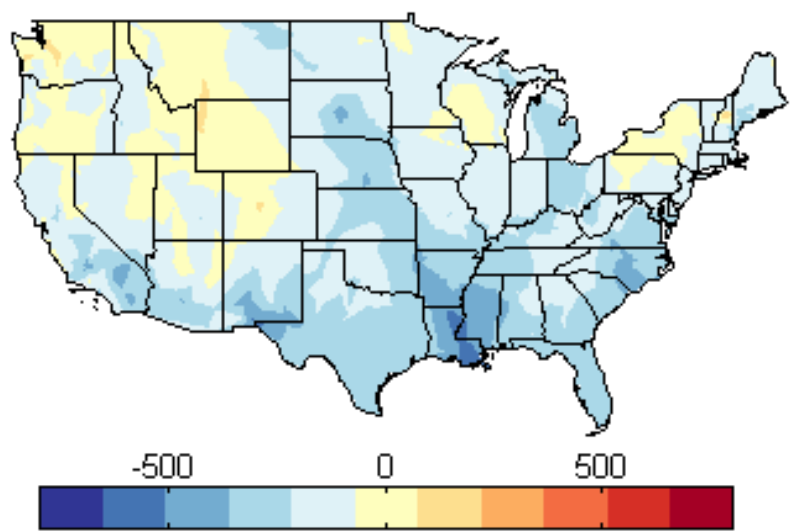

Difference in Annual Energy Produced ( $k$ Wh)
$\mathrm{mc}-\mathrm{Si}$

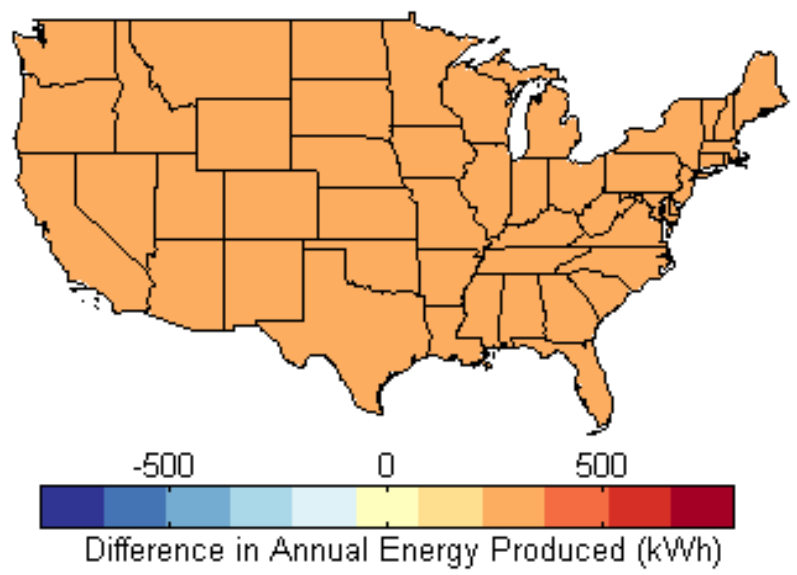

CdTe

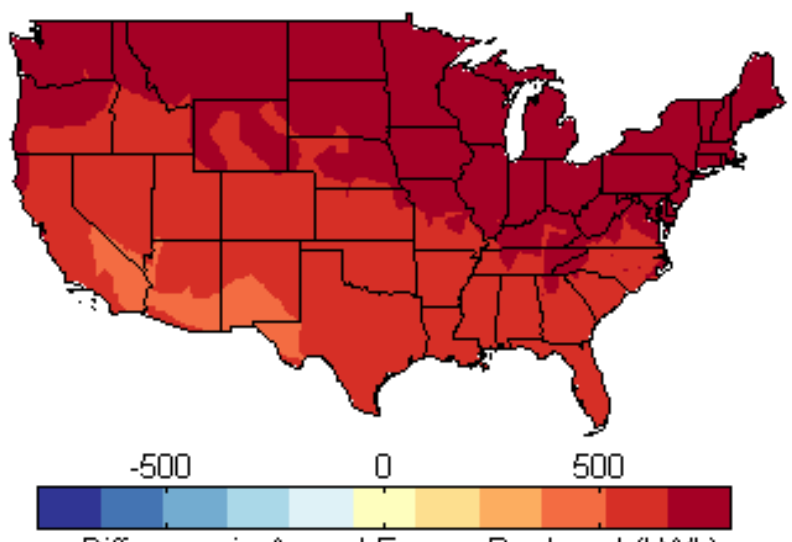

Difference in Annual Energy Produced ( $k$ Wh)

Figure 8: Difference in annual energy production (kWh) between c-Si modules and the 3-a-Si, mc-Si, HIT$\mathrm{Si}$, and $\mathrm{CdTe}$ modules. Positive values indicate that $\mathrm{c}-\mathrm{Si}$ modules produce more energy. 
$3-\mathrm{a}-\mathrm{Si}$
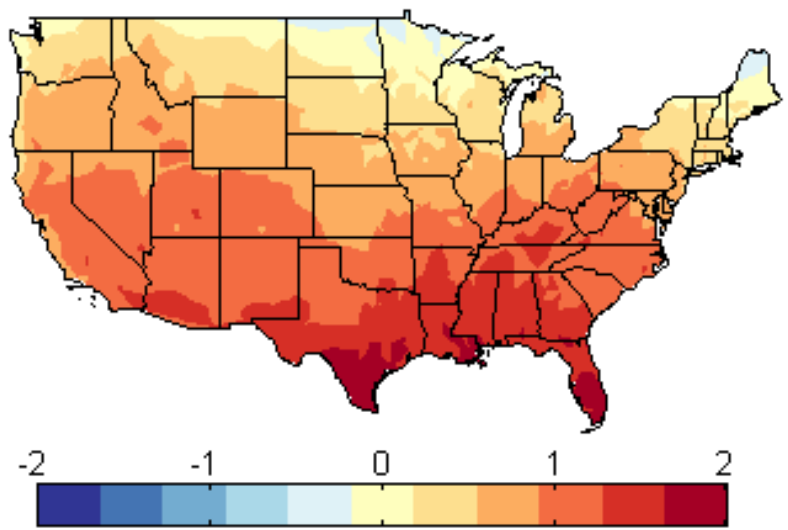

Difference in break-even electricity price ( $\phi / \mathrm{kWh})$

HIT-Si
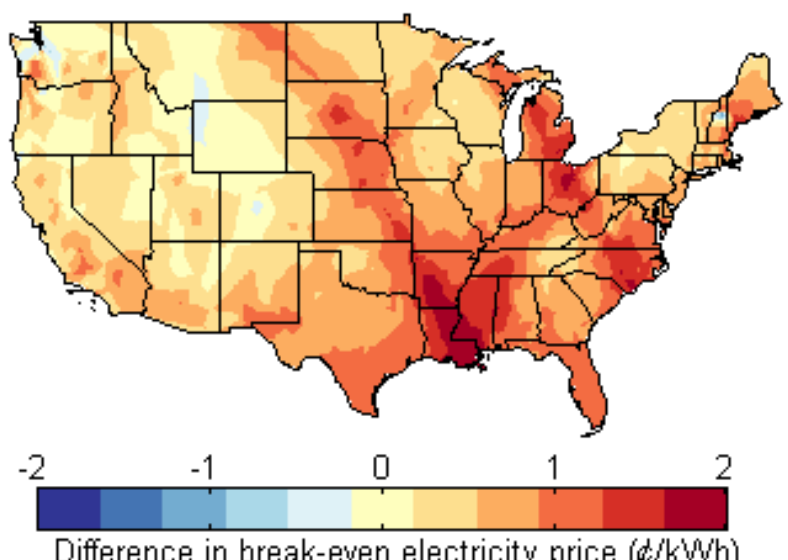

$\mathrm{mc}-\mathrm{Si}$
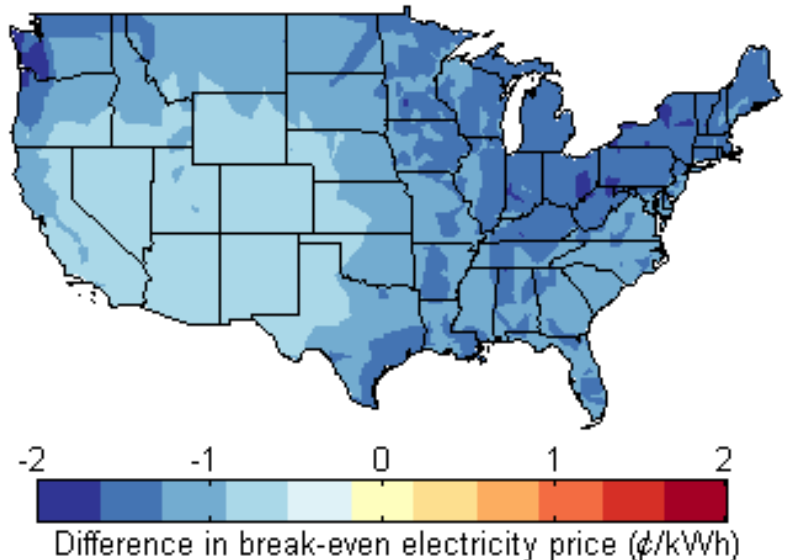

$\mathrm{CdTe}$
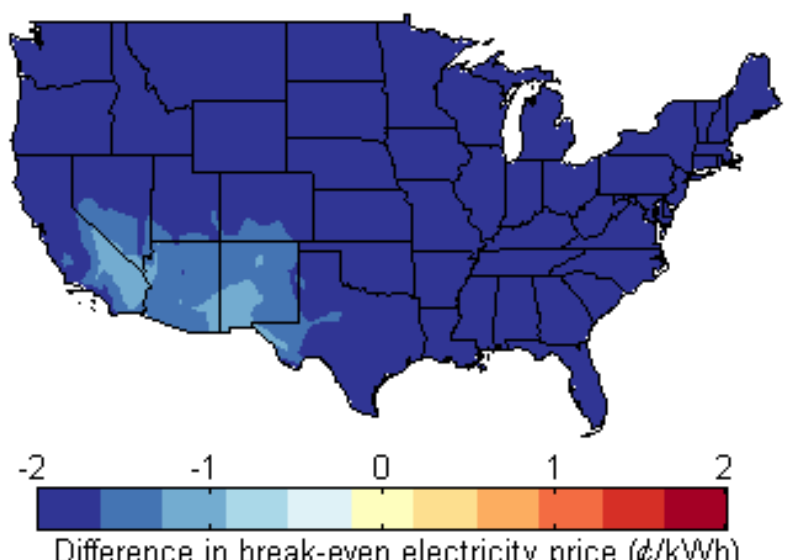

Figure 9: Difference in break-even electricity price ( $\varnothing / \mathrm{kWh})$ between c-Si modules and the 3-a-Si, mc-Si, HIT-Si, and CdTe modules if all modules cost $\$ 4 / \mathrm{W}$. Positive values indicate that the alternative module is more cost effective than the c-Si module. 